\title{
periferio
}

\section{PESQUISA QUANTITATIVA EM EDUCAÇÃO: ALGUMAS CONSIDERAÇÕES}

\author{
Guilherme Pereira ${ }^{1}$ \\ ProPEd/UERJ \\ Maria Isabel Ramalho Ortigão \\ ProPEd/UERJ
}

\section{Resumo}

O presente trabalho busca promover algumas reflexões sobre a produção de pesquisa quantitativa em Educação. Para tanto, encara as metodologias quantitativas como parte integrante de uma lógica de pesquisa mais ampla, que proporcionam retroalimentação, em processos academicamente simbióticos. Parte-se da compreensão de que as metodologias serão escolhidas e utilizadas segundo as perguntas que se pretende responder; logo, há uma relação de macro/micro que é contemplada pela utilização de metodologias quantitativas e qualitativas, sendo que há uma desproporção na razão entre a primeira e a segunda na área. Em seguida, o texto busca apontar alguns aspectos da pesquisa quantitativa com a intenção de esclarecer e indicar possibilidades, sem pretensão de ser um guia definitivo, mas uma apresentação a pesquisadores iniciantes.

Palavras-chave: pesquisa quantitativa; macro/micro; pesquisa educacional; survey

\footnotetext{
1 Doutorando do Programa de Pós-Graduação em Educação da Universidade do Estado do Rio de Janeiro (ProPEd/UERJ). E-mail: guilherme.pereira@uerj.br

${ }^{2}$ Doutora em Educação pela Pontíficia Universidade Católica do Rio de Janeiro (PUC-Rio). Professora da Universidade do Estado do Rio de Janeiro (UERJ). Professora do Programa de Pós-Graduação em Educação, Comunicação e Cultura (PPGECC/UERJ) e do Programa de PósGraduação em Educação (ProPEd/UERJ).
} 


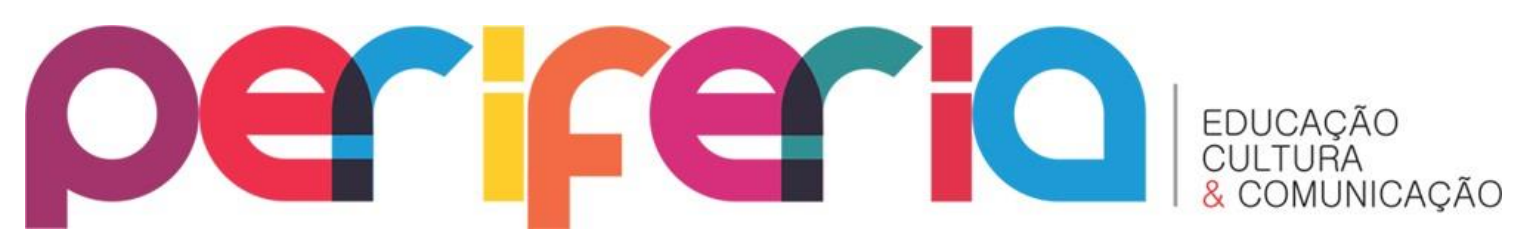

\title{
QUANTITATIVE RESEARCH IN EDUCATION: SOME CONSIDERATIONS
}

\begin{abstract}
The present work seeks to promote some reflections on the production of quantitative research in Education. To this end, it considers quantitative methodologies as part of a broader research logic that provides feedback in academically symbiotic processes. It is based on the understanding that the methodologies will be chosen and used according to the questions to be answered; Therefore, there is a macro/micro relationship that is contemplated by the use of quantitative and qualitative methodologies, and there is a disproportion in the ratio between the first and second in the area. Next, the text seeks to point out some aspects of quantitative research with the intention of clarifying and indicating possibilities, without pretending to be a definitive guide, but a presentation to beginning researchers.
\end{abstract}

Keywords: quantitative research; macro/micro; educational research; survey 


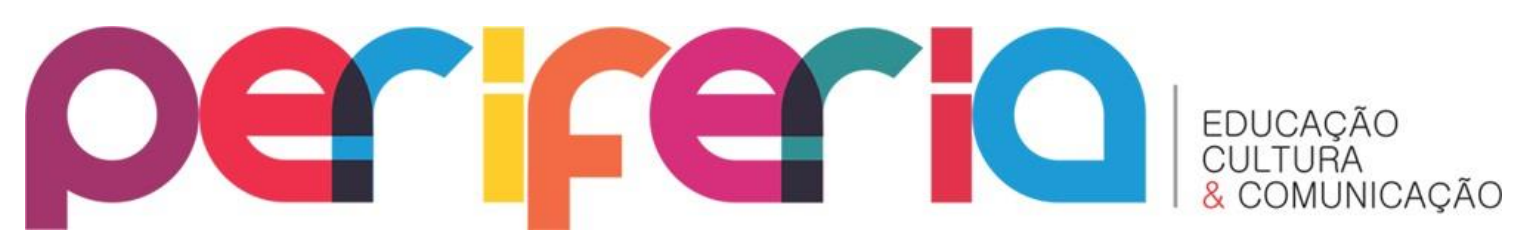

\section{INTRODUÇÃO}

Ao contrário do que pode ser pensado pelo senso comum, realizar pesquisa não é fácil. As diferentes áreas da ciência desenvolvem e operam com métodos pertinentes para avançar em suas pesquisas, segundo suas especificidades. Ao evocar a palavra "cientista", o que vem à mente é alguém de jaleco branco, em um laboratório, operando algum equipamento ou tubos de ensaio, quem sabe lidando com cobaias. A figura que produz ciência, no imaginário popular, trabalha com ciências biológicas e exatas. É essa imagem que tem se construído em nós, enquanto sujeitos sociais (homogeneizando as miríades de variações e sentidos atrelados às significações para efeitos didáticos).

O pesquisador da área das ciências humanas é constituído, pois, em uma crise identitária com a imagem genérica de pesquisador (apesar de considerar que esta ressignificação identitária seja comum a qualquer indivíduo quando se depara com o real, a distância entre o pesquisador das ciências humanas do imaginário popular - do qual todos estes pesquisadores saem - é maior que os pesquisadores das ciências exatas e biológicas do mesmo referencial).

Percebemos que as ciências humanas, na área educacional, operam majoritariamente em metodologias qualitativas, havendo pouca incidência de pesquisas quantitativas. 0 que se mostra como uma manifestação coerente, tendo em vista os referenciais teóricos comuns à área. Contudo, utilizar pesquisas em larga escala contribui para uma visão mais panorâmica das questões. Como seria possível avaliar analfabetismo, perfis de estudantes ou professores, diferenças regionais etc. sem instrumentos de cunho quantitativo que permitissem construir e sintetizar os dados de forma a torna-los operáveis?

O objetivo desse texto é o de buscar promover algumas reflexões sobre a produção de pesquisa quantitativa em Educação. Para tanto, encara as metodologias quantitativas como parte integrante de uma lógica de pesquisa 


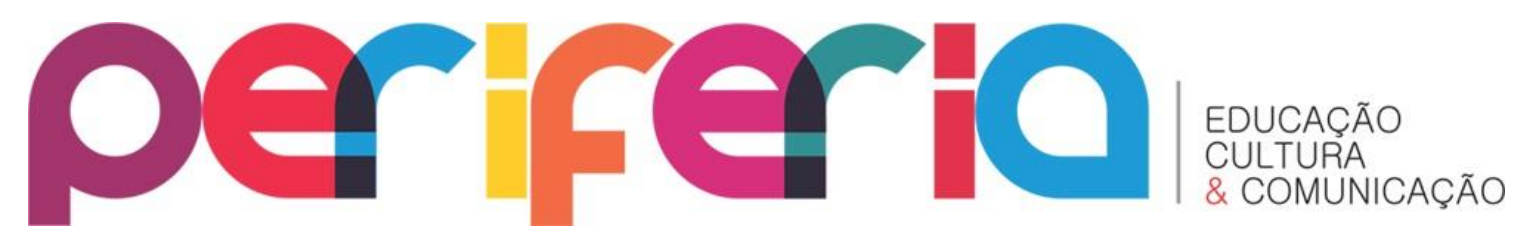

mais ampla, que proporcionam retroalimentação, em processos academicamente simbióticos. Parte-se da compreensão de que as metodologias serão escolhidas e utilizadas segundo as perguntas que se pretende responder; logo, há uma relação de macro/micro que é contemplada pela utilização de metodologias quantitativas e qualitativas.

\section{NO MEIO DO CAMINHO, DADOS QUANTITATIVOS...}

A rejeição, em maior ou menor grau, das pesquisas quantitativas pelo pesquisador genérico das ciências sociais é explicitara por Kelvin Jones, a partir de suas próprias impressões ao oferecer cursos sobre metodologias quantitativas. Para o autor, os pesquisadores que são hostis a tais métodos, o fazem por não compreenderem corretamente do que se trata, e algumas nuances de incompreensão podem ser percebidas, reconhecendo esse tipo de pesquisa como: "trabalhoso, trivial, insensível, reducionista, reacionário e até morto" (JONES in SOMEKH e LEWIN, 2015. p.265.). a) Certamente, realizar pesquisa quantitativa não é um procedimento simples, mas a sensação de ser trabalhoso se deve muito mais ao fato de falta de costume que aos procedimentos em si; há etapas que devem ser seguidas para validação dos instrumentos de pesquisa, por exemplo, sendo que a construção adequada de tais instrumentos contribuirá muito mais para a facilitação do trabalho que o contrário. A trivialidade a qual o autor de refere passa pela adequação da metodologia quantitativa pretendida à pesquisa; para Jones, utilizar a metodologia apenas pela possibilidade de utiliza-la é um "empirismo bobo" (p.265) - é preciso que as questões da pesquisa demandem um viés quantitativo. Pesquisas quantitativas são indicadas para responder a questionamentos que passam por conhecer o grau e a abrangência de determinados traços em uma população, esta também é uma forma de estar sensível aos problemas sociais. Há, nesse tipo de pesquisa, um caráter mais ou menos generalizador; contudo a preocupação em relacionar a pesquisa aos contextos enriquece o trabalho. É, ainda, necessário perceber que trabalhar 


\section{periferio}

com dados estatísticos é operar com um princípio de incerteza; tais dados apontam frequências e indicativos, mas, de modo algum representam fielmente a realidade (se é que isso seja possível em qualquer pesquisa que seja!). A história tem mostrado que a ciência não é neutra e que tem sido utilizada para justificar e validar os mais diversos tipos de políticas; não é diferente com a metodologia quantitativa. Porém, não é a metodologia a ser reacionária, mas as possíveis utilizações dela, sobretudo por seu caráter panorâmico, que pode ser distorcido para dar falsas ideias democráticas, por exemplo. E, finalmente, sobre a falta de vitalidade das pesquisas quantitativas, não poderia haver maior engano; há manifestação dela em diversas áreas, com milhares de trabalhos anuais. É pungente que os diversos tipos de pesquisa sejam considerados como complementares, no sentido de produzirem olhares diversos sobre uma mesma questão. A produção de resultados de cunho quantitativo complementa e promove questões e pesquisas metodologicamente pautadas em teorias qualitativas, e vice-versa. Esta retroalimentação é, na verdade, um princípio básico da produção científica.

Nas ciências sociais, a relação entre os olhares quantitativos e qualitativos podem ser abarcados em uma lógica de análise macro/micro. Estas análises, segundo Alice Casimiro Lopes (2006) precisam ser lidas de forma relacional.

Dessa forma, é preciso interpretar as relações entre as diferenças sem congelá-las em um modelo único e fixo. Não se trata de produzir uma generalização da multiplicidade de efeitos locais para produzir um fenômeno global, mas de entender as conexões mutuamente constitutivas entre o global e o local, entre o específico e o geral. (LOPES, 2006, p. 633)

\section{E NA EDUCAÇÃO...}

Bernardete Gatti (2004), ao tratar da utilização das metodologias em Educação, pontua que, geralmente, há duas considerações importantes: 


\section{periferio}

...primeiro, os números, frequências, medidas, tem algumas propriedades que delimitam as operações que se podem fazer com eles, e que deixam claro seu alcance; segundo, que as boas análises dependem de boas perguntas que o pesquisador venha a fazer, ou seja, da qualidade teórica e perspectiva epistêmica na abordagem do problema, as quais guiam as análises e as interpretações. (p.13)

E, além disso "em si, tabelas, indicadores, testes de significância, etc. nada dizem. O significado dos resultados é dado pelo pesquisador em função de seu estofo teórico" (GATTI, 2004, p.13).

Tais ponderações ressaltam o caráter incompleto dos dados em si, no sentido de que sempre demandam interpretação, sempre serão lidos sob uma ou outra ótica que lhe farão significar isto ou aquilo. E, além disso, a própria ideia de dados enquanto constructo, sem algo a priori. Dados surgem das perguntas de pesquisa; são uma resposta àquilo que o pesquisador levanta. Mesmo dados mais objetivos como idade, escolaridade, estado civil etc., serão partes constituintes de uma pesquisa na medida em quem fizerem sentido no conjunto argumentativo construído pelo pesquisador. "Os cientistas nunca coletam dados, eles criam dados”. (BABBIE, 1999. p. 181)

Gatti (2012) considera que as pesquisas educacionais são uma seara na qual carecem traquejo e matéria prima para a realização de trabalhos, que, como dito, são escassos quando comparados aos trabalhos de natureza estritamente qualitativa. Há questões de pesquisa que demandam uma abordagem qualitativa e outras, uma abordagem quantitativa; mesmo que uma pesquisa acadêmica, ainda que pautada na construção de dados quantitativos, sempre seja constituída, inclusive, da análise dos dados em um viés qualitativo. Por este motivo, muitos pesquisadores denominam suas pesquisas como mista ou quali-quanti.

Pesquisas quantitativas e qualitativas não são polos opostos e antagônicos; são complementares e oferecem diferentes perspectivas. Uma possibilidade para compreender melhor é pensarmos em um modelo escalonado. Ao reproduzir um objeto em uma imagem, é preciso considerar a 


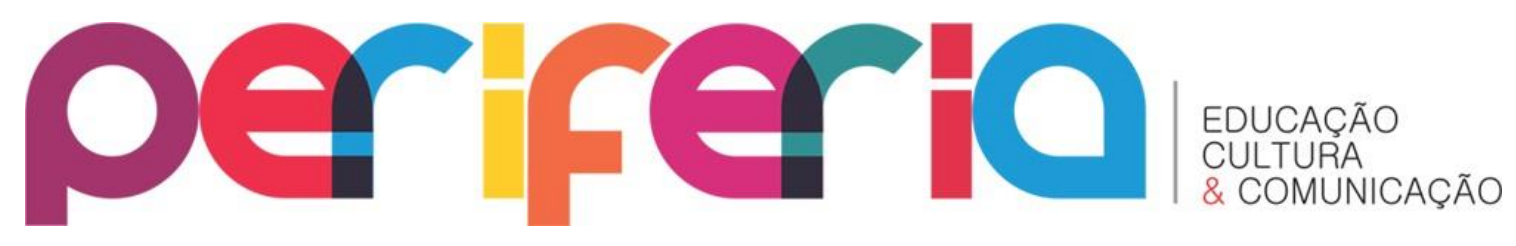

relação do tamanho real com o tamanho da imagem; quanto maior a área representada, menor o detalhamento contido na imagem; quanto menor o recorte do objeto original, maior a possibilidade de copiar os detalhes. Esta analogia da representação pictográfica mostra, também, que as pesquisas apresentam apenas algumas impressões sobre o objeto analisado, sendo possíveis outros ângulos ou reflexões sobre outras camadas dos objetos. 0 escalonamento se refere à aproximação com fim de perceber detalhes finos; ou afastamento para percepção de um conjunto amplo; uma relação entre uma perspectiva microscópica ou uma perspectiva panorâmica.

Investir em pesquisas de caráter quantitativas (ou mistas, ou qualiquanti) contribui para a compreensão de relações mais amplas. Esta não é uma tarefa simples, principalmente por, como dito por Gatti (2004), haver menos inserção da área educacional como um todo, o que se desdobra com muita facilidade em menor contato de profissionais da educação com metodologias quantitativas em suas formações. 0 investimento, portanto, deve ser no sentido de compreender a lógica de funcionamento desses tipos de pesquisa, de saber lidar com os dados apresentados e sua complexidade, muitas vezes traduzidas pela mídia em uma lista de rankeamentos quando se trata de educação.

Pesquisadores que decidem trabalhar com métodos quantitativos tendem a sentir dificuldade e insegurança quanto ao modo de realizar a pesquisa, tendo em vista a inexperiência diante de procedimentos supostamente novos. A seguir, serão apresentadas algumas indicações que podem ajudar em um primeiro momento, baseadas nas produções de autores com produção extensa que pode contribuir muito mais. A ênfase será em surveys autoadministrados, mas a ideia principal pode ser adaptada a outras metodologias. 


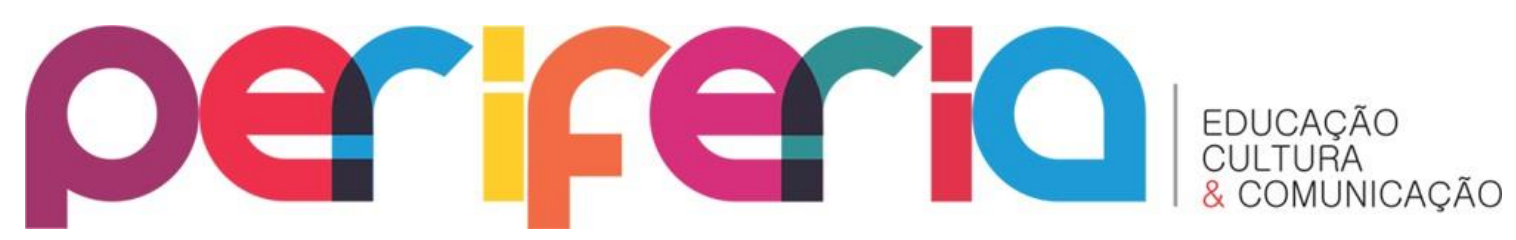

\section{ALGUMAS INDICAÇÕES METODOLÓGICAS}

Um instrumento recorrente na pesquisa quantitativa é o survey, que consiste, basicamente, em um conjunto de questões padronizadas apresentadas a uma amostra populacional. A diferença entre survey e censo está neste recorte, o primeiro seleciona uma amostra, enquanto o segundo opera com toda a população. Sendo um instrumento empírico, há várias possibilidades de desenhar um survey, a depender da finalidade (BABBIE, 1999).

Babbie elenca três categorias de survey quanto ao interesse de sua utilização para a pesquisa: surveys para descrição, com o objetivo de mapear traços distribuídos pela amostra; surveys para explicação, que, além de descrever os traços, busca realizar asserções que expliquem os cenários; surveys para exploração, que fazem emergir categorias para outras etapas da pesquisa. Deve ficar claro que o survey não é a pesquisa, mas parte dela.

Os tipos de survey indicados por Babbie salientam a importância das categorias de análise a serem utilizadas na pesquisa como elementos centrais e primários; duas das três partem do princípio de que estas categorias já estão estabelecidas na pesquisa a partir de vasta revisão da literatura e, a terceira, indica que, em alguns casos, há a necessidade de buscar tais informações a partir de instrumento empírico.

Para o autor (BABBIE, 1999), questionários de pesquisa precisam estar apoiados em referências teóricas, decorrente de um acurado exame da literatura específica. Ortigão (2009) sugere que tal exame seja o resultado de um processo interativo entre pesquisas de cunho qualitativo e quantitativo e a análise de diferentes tipos de questões encontradas nos diversos questionários de levantamento educacional aos quais tive acesso.

Estruturar um quadro referencial é importante para, em primeiro lugar, elaborar questões pertinentes que sejam coerentes, façam sentido dentro do escopo de pesquisa e, apetecivelmente, permitam desdobramentos em modelos de referência cruzada, por exemplo. Um equívoco comum é investir 


\section{periferio}

esforços em aplicar questionários ou entrevistas sem uma base teórica construída. Essa situação não é desejável, pois pode desperdiçar tempo e trabalho, produzindo respostas superficiais e pouco úteis ao trabalho.

Além disso, segundo Babbie (1999), os conceitos mais importantes e de interesse ao pesquisador, de modo geral, não são observáveis diretamente ${ }^{3}$, o que demanda que pressupor que se busque uma aproximação do que se quer observar.

As questões de pesquisa (ou de interesse ao pesquisador) precisam estar relacionadas aos conceitos, comportando um aprofundamento para além do que já foi observado na literatura. Como ilustração, imaginemos que uma prefeitura esteja reformulando seu quadro médico e precise saber quantos cidadãos precisam de tratamento otorrinolaringológico e fonaudiológico referente à perda de audição para reformular o quadro de funcionários. Alguém que não conhece da área poderia realizar um censo perguntando sobre a presença de surdos nas casas. Isso seria um problema por haver um espectro de diferentes níveis de perda auditiva indo de uma perda parcial leve a perda total; ignorando também as questões culturais e políticas de assumir-se ou não enquanto surdo. Duas pessoas com o mesmo índice de perda podem se identificar de forma distinta, como surdo ou como deficiente auditivo. 0 mesmo pode ser pensado para o atendimento adequado a alunos da rede municipal de ensino quanto à disponibilidade de intérpretes.

Outro exemplo de pesquisa quantitativa, no campo da Educação, foi a desenvolvida por Ortigão (2005), no âmbito de seu doutorado. Com o objetivo de compreender o que professores de matemática selecionam para o ensino dessa disciplina e em que medida esta seleção é impactada por características do perfil socioeconômico e cultural dos estudantes da escola, um estudo do tipo survey foi desenhado envolvendo (a) seleção de amostra, (b) aplicação de questionário a professores e a estudantes, construídos especificamente para a pesquisa e (c) análise dos resultados obtidos.

\footnotetext{
${ }^{3}$ Babbie (1999) denomina esses conceitos de latentes ou não-observáveis.
} 


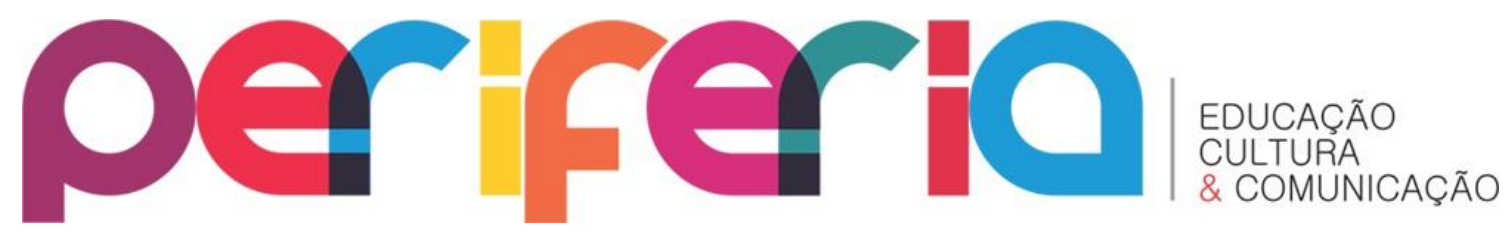

Para a autora, o desenho do instrumento de coleta de dados foi desenhado pressupondo a existência de conceitos latentes e à possibilidade de construção de escalas. Para ela,

quando usamos escalas, as respostas estão pré-determinadas e o respondente, no caso professor, é solicitado a se posicionar, instituindo, dessa forma, uma situação que se diferencia de outras nas quais, por exemplo, o professor pode falar sobre como trabalha com os alunos. Por conta disso, abre-se mão de conclusões pontuais, centradas no indivíduo, porque não são oferecidas oportunidades para trabalhar com os particulares, com os detalhes, com as nuances que de fato caracterizam cada um dos indivíduos e sua opinião. 0 uso de escalas viabiliza uma fotografia panorâmica em um dado espaço e tempo, tendo como foco o que escolhemos para definir resolução de problemas, automatização e trabalho conjunto, bem como quanto aos procedimentos usados pelos docentes para avaliar formalmente os seus alunos. Nesse sentido, os resultados apresentados permitem entender os professores enquanto grupo, e não enquanto indivíduos. Mais ainda, enquanto grupo que precisou se posicionar nas alternativas de respostas apresentadas no instrumento para enunciados bastante específicos. (ORTIGÃO, 2009, p. 128)

Para Ortigão (2007) na produção de instrumentos de coleta de dados para pesquisa que operam com muitas questões, é necessária a atenção aos aspectos operacionais, tais como: formatação, clareza da linguagem, ordenamento das questões, bem como para o favorecimento da entrada das respostas. Detalhes podem fazer a diferença em ter ou não a participação das pessoas em responder às questões, ou o compromisso com a sinceridade etc. Os instrumentos autoadministráveis devem iniciar com instruções muito claras quanto ao seu preenchimento. É primordial que a linguagem esteja adequada, inclusive, para que os respondentes sintam-se a vontade com o procedimento. Uma linguagem inadequada pode criar a sensação de exame, ou de algo sem importância. Nem sempre é possível repetir a aplicação de instrumentos de pesquisa, portanto, faz-se fundamental que cada pormenor seja pensado antecipadamente, durante o planejamento da pesquisa. 


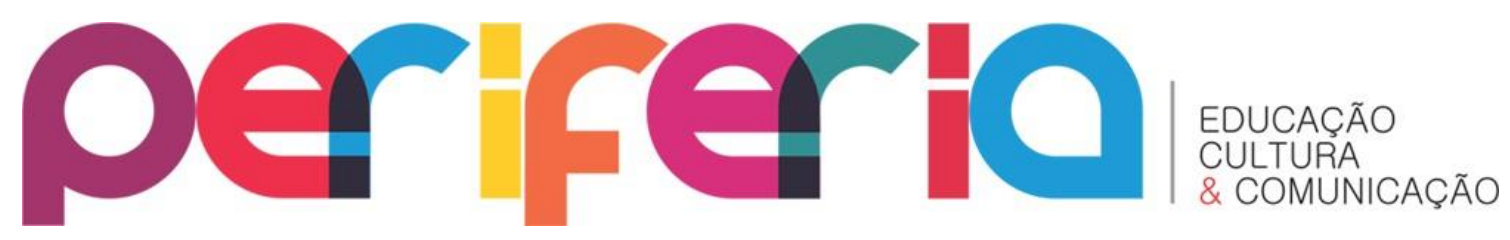

Babbie (1999) sugere que, na organização de um questionário, os itens, independentemente de sua natureza, sejam ordenados dos mais relevantes para a pesquisa e instigantes ao respondente para os menos relevantes e instigantes. Instrumentos de pesquisa costumam ser grandes e podem ser cansativos, deixar itens menos relevante ou menos cansativos para o final ajuda a garantir a qualidade das respostas principais; questões objetivas e observáveis, por exemplo, como idade, local de nascimento, profissão... Ou seja, informações que não demandam reflexão dos respondentes, podem ser deixadas para o final do instrumento, além de evitarem a associação com um formulário rotineiro.

Ainda segundo Babbie, os itens devem : a) ser claros, com frases precisas e que não se estendam para além do necessário para que o respondente saiba do que se trata (e é preciso lembrar que nem sempre a temática está tão esclarecida para os respondentes quanto para o pesquisador); b) ser singulares, não atrelando duas ou mais declarações a uma mesma resposta já que o respondente poderia ter posicionamentos distintos para cada uma das declarações; c) ser passíveis de resposta, evitando ou considerando a incerteza de algumas questões por serem muito específicas e demandarem um esforço mnemônico impraticável; d) ser relevantes, no sentido de, sempre que possível, dar a oportunidade de não responder como uma resposta válida, evitando que o respondente minta para não deixar de responder; e) ser curtos, deduzindo que, dado o percurso do instrumento, os respondentes lerão os enunciados rapidamente e responderão rapidamente, então, novamente, é necessário que estes sejam tão curtos quanto o possível para garantir a compreensão da questão; f) ser positivos, pois declarações ou questões com partículas negativas em sua constituição tendem a ser lidas erroneamente, com a partícula negativa ignorada; g) evitar termos tendenciosos, como as partículas negativas que podem induzir o respondente a posicionar-se negativamente sobre as questões, mesmo que este não seja um exemplo tão sutil quanto os que se manifestam em diversos instrumentos. 


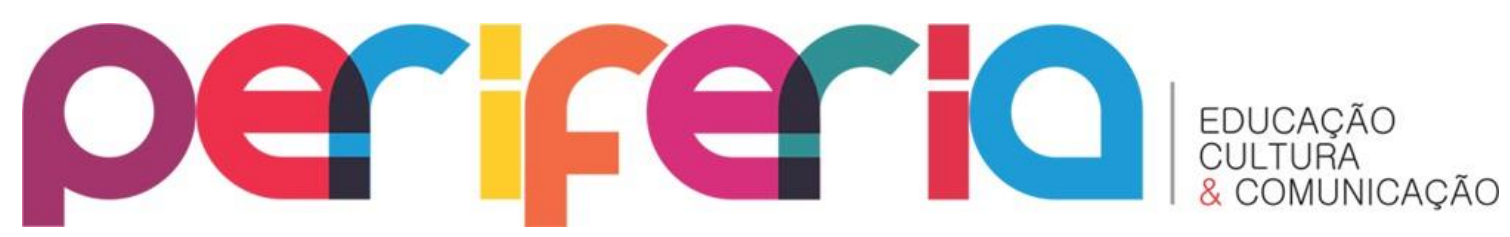

Outro fator a ser considerado é a confiabilidade dos itens. Isto tem a ver com o comportamento semelhante de diferentes respondentes diante de um mesmo item. Ortigão e Pereira (2016) salientam que, em avaliação educacional, a utilização do DIF - Differential Item Functioning - tem sido tomada como recurso para garantir que grupos diferentes de estudantes com a mesma proficiência tenham a mesma probabilidade de ter êxito na resposta de um dado item, ou seja, o DIF possibilita verificar a variação da dificuldade do item para grupos que tem a mesma capacidade cognitiva, o que aponta para a incidência de variáveis outras que interferem no resultado.

Ainda sobre a criação dos itens, é importante ter sempre em mente o que se deseja fazer com as respostas que eles suscitam; como estas contribuem e se encaixam na pesquisa. Um caminho provável é a transformação das respostas em índices ou escalas ${ }^{4}$, distintos entre si pelo fato de o primeiro ser um somatório simples entre as respostas a um item e o segundo indicar uma variação de intensidades nas respostas.

Já deve estar claro que há muito a ser considerado na produção de um instrumento de pesquisa, e que tal instrumento não é o princípio nem o fim de uma pesquisa. A utilização de um instrumento validado garante que o mesmo tenha sido corrigido o suficiente para assegura sua pertinência e legitimidade.

\section{CONCLUSÃO}

O aprofundamento nas reflexões teóricas da temática de pesquisa, bem como a apropriação da metodologia de pesquisa são etapas indispensáveis para o bom desenvolvimento do trabalho. A aplicação do instrumento

\footnotetext{
${ }^{4}$ Segundo Ortigão (2009), escalas são dispositivos formulados com o intuito da redução de dados, uma vez que várias respostas de um respondente podem ser reduzidas em um único valor, que expresse uma medida para o conceito latente pretendido. As escalas, quando bem construídas, permitem ordenar os respondentes em função dos conceitos latentes que orientaram a sua proposição
} 


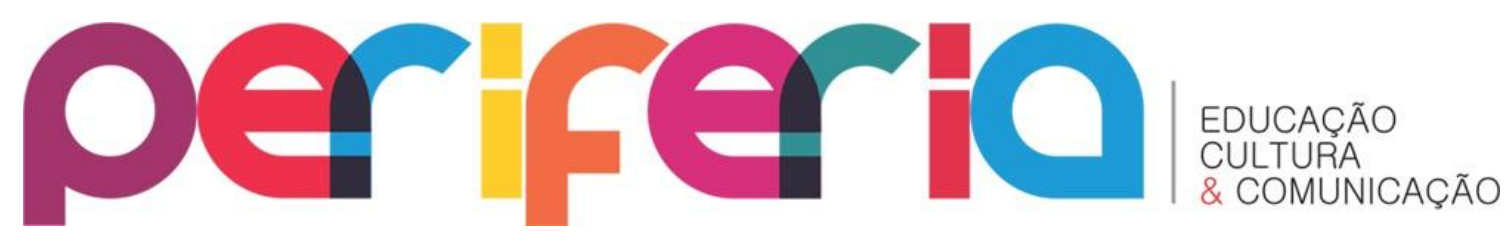

demandará sistematização e análise das respostas frente ao quadro conceitual construído e o tratamento dos dados por softwares pode contribuir bastante para leituras mais complexas.

Compreender a importância dessas pesquisas para o enriquecimento do conhecimento sobre os diversos cenários educacionais mostra-se como uma necessidade urgente frente a crescente utilização de dados quantitativos atrelados a políticas educacionais que, muitas vezes são fetichizados em uma espécie de ciência verdadeira dado o seu caráter matemático, trazendo um quê de inquestionabilidade que deve ser rechaçado. É de interesse geral que os profissionais da educação, sobretudo professores, tomem para si a capacidade de lidar com dados quantitativos, bem como refletir sobre suas análises.

O survey enquanto método de pesquisa mostra-se relevante no âmbito educacional devido ao seu caráter amostral. 0 rigor da pesquisa indica possibilidade de generalização a partir de uma amostragem, o que é útil quando o acesso a população total é inviável. É preciso salientar que generalizar não significa homogeneizar, ou considerar que o resultado representa a realidade de maneira absoluta e fidedigna. Nenhuma pesquisa, independe de sua natureza, seria capaz disso. Estamos sempre operando em uma lógica de incerteza, produzindo possibilidades de leitura a partir de uma construção social discursivamente elaborada.

Nesse sentido, movimentos de investida nas análises do macro são tão importantes para pensar as questões educacionais quanto as microanálises.

É uma ilusão imaginar que a multiplicação de análises micro sociais permitiriam a reconstrução das configurações sociais gerais (estruturais), ou que pode-se chegar a essas configurações pela reconstrução diversificada e ampliada das configurações particulares. 0 mundo da experiência tem uma capacidade inesgotável de recriar e construir novas formas de interações e padrões coletivos de valores que produzem em ações significativas complexas no plano individual (interações face a face) quanto no plano macrossocial. A arte do pesquisador estaria exatamente na sua capacidade de escolher 


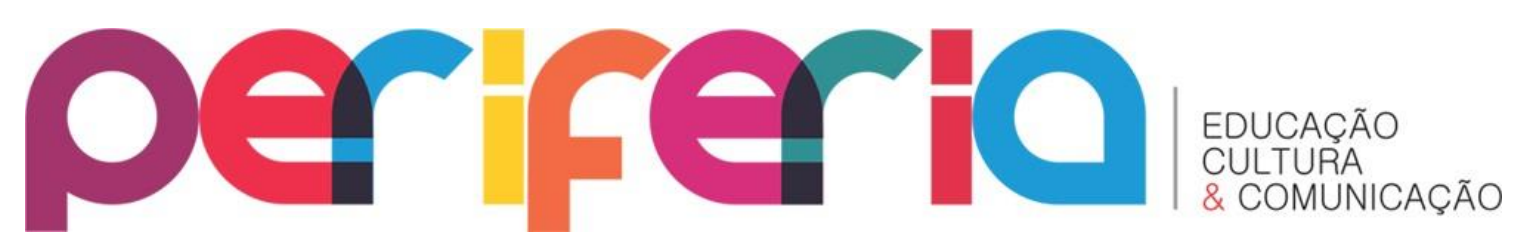

o instrumento de análise mais adequado ao problema de pesquisa e as possibilidades empíricas do campo de investigação. (BRANDÃO, 2001)

Não se trata de escolher entre uma coisa ou outra de maneira absoluta e excludente, mas de perceber que ambas podem ser válidas e que se constituem como instrumentos pertinentes a depender das questões de pesquisa postas. Nenhuma pesquisa representará a totalidade, mas diferentes lentes podem contribuir para reflexões que avancem na possibilidade de compreender para além do óbvio e do diretamente observável.

\section{REFERÊNCIAS BIBLIOGRÁFICAS}

BABBIE, Earl. Métodos de pesquisas de survey. Belo Horizonte: UFMG, 1999.

BRANDÃO, Z. A dialética macro/micro na sociologia da educação. Cadernos de Pesquisa, São Paulo, São Paulo, n. 113, p. 153-165, jul. 2001.

GATTI, B. A. Estudos quantitativos em educação. Educação e Pesquisa, São Paulo, v. 30, n. 1, p. 11-30, jan./abr. 2004.

- A construção metodológica da pesquisa em educação: desafios.

Revista Brasileira de Política e Administração da Educação. v. 28, n. 1, p. 13 34, jan/abr. 2012.

LOPES, A. C. Relações macro/micro na pesquisa em currículo. Cadernos de Pesquisa, São Paulo, São Paulo, v. 36, n. 129, p. 619-635, set/dez. 2006.

ORTIGÃO, M. I. R; PEREIRA, T. V. Homogeneização curricular e o sistema de avaliação nacional brasileiro: o caso do estado do Rio de Janeiro. Educação, Sociedade \& Culturas. v. 47, n. 1, p. 157-174, 2016.

ORTIGÃO, M. I. R. Sala de aula de Matemática: a avaliação das práticas docentes. BOLEMA - Boletim de Educação Matemática. Rio Claro (SP). Ano 22, $N^{\circ} 33,2009$, p. 117-140.

ORTIGÃO, M. I. R. Currículo de matemática e desigualdades educacionais. 2005. 194 f. Tese (Doutorado) - Departamento de Educação, Pontifícia Universidade Católica do Rio de Janeiro.

SOMEKH. B; LEWIN, C. Teoria e métodos de pesquisa social. Petrópolis, RJ: Vozes, 2015. 